\title{
Understanding Liver Regeneration
}

\section{From Mechanisms to Regenerative Medicine}

\author{
Hélène Gilgenkrantz* and Alexandra Collin de l'Hortet
}

From INSERM U1149,* Center for Research on Inflammation, Université Paris Diderot, Sorbonne Paris Cité, Paris, France; and the Department of Pathology, ${ }^{\dagger}$ University of Pittsburgh, Pittsburgh, Pennsylvania

Accepted for publication March 23, 2018.

Address correspondence to Hélène Gilgenkrantz, M.D., Ph.D., Centre de Recherhe sur l'Inflammation, Faculté de Médecine Xavier Bichat, 16 Rue Huchard, 75018 Paris, France. E-mail: helene. gilgenkrantz@inserm.fr.

\begin{abstract}
Liver regeneration is a complex and unique process. When two-thirds of a mouse liver is removed, the remaining liver recovers its initial weight in approximately 10 days. The understanding of the mechanisms responsible for liver regeneration may help patients needing large liver resections or transplantation and may be applied to the field of regenerative medicine. All differentiated hepatocytes are capable of self-renewal, but different subpopulations of hepatocytes seem to have distinct proliferative abilities. In the setting of chronic liver diseases, a ductular reaction ensues in which liver progenitor cells (LPCs) proliferate in the periportal region. Although these LPCs have the capacity to differentiate into hepatocytes and biliary cells in vitro, their ability to participate in liver regeneration is far from clear. Their expansion has even been associated with increased fibrosis and poorer prognosis in chronic liver diseases. Controversies also remain on their origin: lineage studies in experimental mouse models of chronic injury have recently suggested that these LPCs originate from hepatocyte dedifferentiation, whereas in other situations, they seem to come from cholangiocytes. This review summarizes data published in the past 5 years in the liver regeneration field, discusses the mechanisms leading to regeneration disruption in chronic liver disorders, and addresses the potential use of novel approaches for regenerative medicine. (Am J Pathol 2018, 188: 1316-1327; https://doi.org/10.1016/j.ajpath.2018.03.008)
\end{abstract}

In epithelial tissues with high turnover, such as the intestines and the skin, cellular renewal and tissue homeostasis is performed by a pool of stem cells. In the liver, however, the turnover is low and the general assumption, until recently, was that all mature hepatocytes were able to divide to provide normal liver homeostasis. ${ }^{1,2}$ Most knowledge of liver regeneration comes from the rodent model of twothirds partial hepatectomy (PHx). In this model, $66 \%$ of the liver is resected, leaving an undamaged remnant liver. After mouse PHx, mature quiescent adult hepatocytes of this remnant liver enter the cell cycle in a semisynchronous manner.

Three phases have traditionally been described in the liver regeneration process. The first phase is called the priming phase and prepares hepatocytes to answer to growth factors. During this step, $>100$ genes become activated in a few minutes after PHx. The second phase after the priming phase corresponds to the activation of growth factor receptors. Among them, epidermal growth factor receptor (EGFR) and c-Met are both essential for liver regeneration and act synergistically: their combined systemic elimination completely abolishes the regenerative process and leads to ascites and hyperammonemia. In contrast, the invalidation of either $c$-Met or EGFR induces regenerative defects by delaying hepatocyte proliferation. ${ }^{3}$ Finally, the last step of the liver regeneration process is cessation of proliferation. Until now, pathways identified as important inhibitors of liver regeneration during the termination phase included transforming growth factor- $\beta$ and integrin signaling, which mediates communication between the extracellular matrix and epithelial cells. In this review, we discuss the recent data that have modified our vision of this tightly orchestrated regeneration process in normal state and in chronic liver diseases. In addition, we discuss the potential and

Disclosures: None declared. 

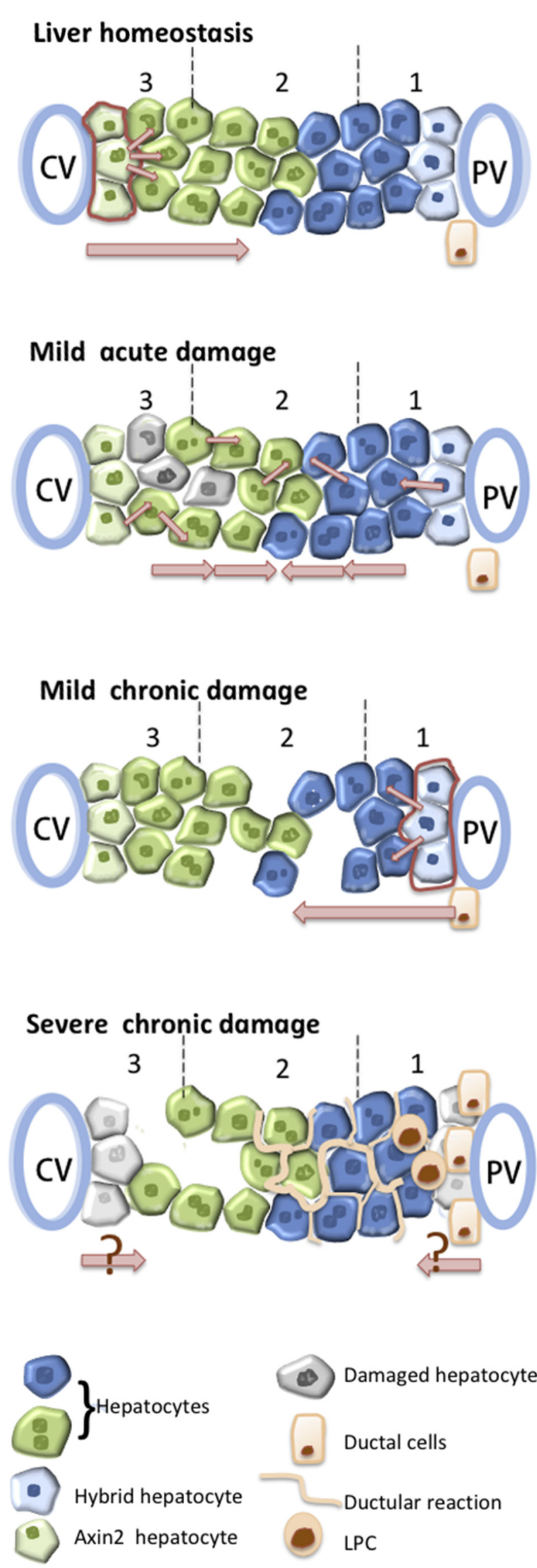

challenges of using liver regenerative approaches for medicine and research.

\section{Hepatocytes Harbor a Heterogeneous Capacity to Proliferate}

From a metabolic perspective, the functional unit of the liver is the lobule: hepatocytes located in the periportal zone 1 are specialized in gluconeogenesis and $\beta$-oxidation, whereas hepatocytes located around the central vein (zone 3 ) are more important for glycolysis, lipogenesis, and detoxification. Thus, hepatocytes are functionally heterogeneous. They express different genes, depending on their location in the hepatic lobule along the portocentral axis. This metabolic zonation allows the liver to respond to different nutritional requirements or hepatotoxins. Unexpectedly, lineage-tracing experiments in mice, in the absence of any liver injury, have recently identified a population of proliferating and selfrenewing hepatocytes in the centrilobular zone 3 , adjacent to

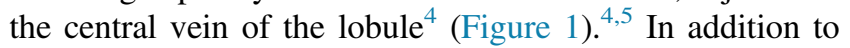
expressing some early liver progenitor markers, such as $T b \times 3$, and the Axin $2 \mathrm{Wnt} / \beta$-catenin target gene, these cells were shown to proliferate twice as fast as the other hepatocytes and replace more than one-third of the mouse liver lobule around the central vein during homeostatic renewal in approximately 1 year. ${ }^{4}$ The stem cell characteristics of these hepatocytes depend on the expression of Wnt ligands by nearby endothelial cells. This new vision of the hepatostat will, however, require further investigations, especially because a recent study failed to provide evidence of a hepatocyte niche around the central vein responsible for liver homeostasis and did not find higher proliferation rate of pericentral hepatocytes. ${ }^{6}$

In zone 1, near the portal triad, lies another population of hepatocytes with a potential proliferative advantage over noncentrilobular hepatocytes. ${ }^{5}$ These periportal hepatocytes have been called hybrid hepatocytes because, besides their expression of progenitor markers, such as Sox9, they are enriched both in bile duct-specific genes and in hepatocytespecific transcription factors, such as $H n f 4 \alpha$. Hybrid hepatocytes are able to reconstitute the liver mass after various chronic injuries, ${ }^{5}$ and they may represent a novel therapeutic tool in cell-based therapy approaches. However, these

\footnotetext{
Figure 1 Schematic representation of cells involved in regeneration, depending on the type of injury. In mouse liver homeostasis, axin2positive hepatocytes (pale green) located around the central vein have a higher proliferative capacity than hepatocytes located in mediolobular (green and blue) or in periportal (pale blue) area. ${ }^{4}$ After a mild acute damage, nondamaged hepatocytes enter into the cell cycle. After a mild chronic damage, hybrid hepatocytes located around the portal vein (pale blue) preferentially repopulate the liver. ${ }^{5}$ A severe chronic liver damage induces a ductular reaction composed of ductal cells and liver progenitor cells (LPCS). It is not yet determined whether these cells participate in liver regeneration in human pathologic conditions. Zone 1 corresponds to the periportal region, zone 2 corresponds to the intermediate region, and zone 3 corresponds to the centrilobular region. CV, central vein; PV, portal vein.
} 
Type of resection

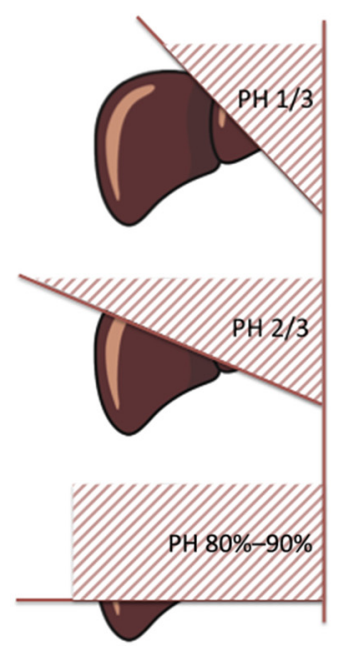

Type of regeneration

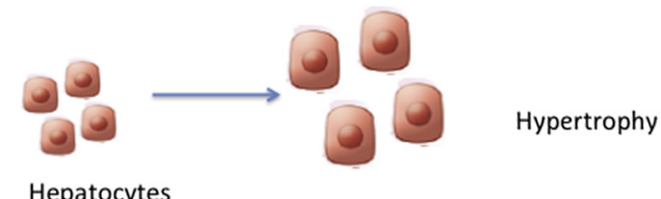

Hepatocytes
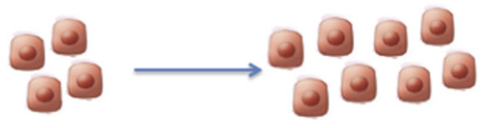

Hyperplasia

$\mathrm{BEC}$

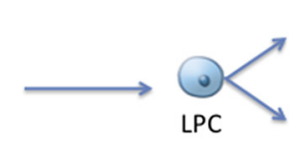

Dedifferentiation/ redifferentiation
Figure 2 The volume of the withdrawn liver determines the type of regeneration. To restore the initial liver mass after liver surgery, hepatocytes respond by enhancing their volume after one-third partial hepatectomy (PH), whereas they respond with proliferation after two-thirds $\mathrm{PH}$. When $80 \%$ to $90 \%$ of the liver is resected, biliary epithelial cells (BECs) dedifferentiate in progenitor cells and repopulate the liver. LPC, liver progenitor cell. hepatocytes likely do not participate in normal liver homeostasis, in contrast to the pericentral population.

Major facilitator superfamily domain containing $2 \mathrm{a}$ (Mfsd2a) is a marker of periportal hepatocytes. Using a genetic lineage strategy, it was found that $\mathrm{Mfsd} 2 \mathrm{a}^{+}$periportal hepatocytes were replaced with $\mathrm{Mfsd}_{2} \mathrm{a}^{-}$hepatocytes migrating from the pericentral area during liver homeostasis, comforting previously reported results. ${ }^{4}$ In contrast, Mfsd $2 \mathrm{a}^{+}$ periportal hepatocytes expand as a compensatory growth response after liver resection or chronic toxic liver injury. ${ }^{7}$ The metabolic zonation is then reestablished by the reprogramming of the Mfsd2 $\mathrm{a}^{+}$-derived hepatocytes to Mfsd2a $\mathrm{a}^{-}$hepatocytes in pericentral hepatocytes. The lobule should thus now be seen as an anatomical unit with different hepatocyte populations more prone to restore the liver mass, depending on the type of injury (Figure 1). Moreover, it has been shown that hepatocytes located near endothelial cells proliferate more rapidly than more distant hepatocytes. ${ }^{8}$ If the site, the type, and the duration of injury determine the cell type recruited and the site of proliferation, there is no contradiction in postulating that hepatocytes proliferate in opposite or various regions of the lobule that will align along the endothelium and stop dividing once the initial mass has been reached. Altogether, these results uncover a novel characteristic of hepatocytes (ie, their heterogeneous ability to proliferate).

\section{Various Regeneration Stimuli Trigger Different Regenerative Responses}

Drastic measures have been taken to understand the true capacity of the liver to regenerate. What is responsible for the restoration of the rodent liver mass after resection in $<14$ days: hyperplasia, an increased rate of hepatocyte proliferation or hypertrophy (ie, an increase in cell size)? Until recently, it was thought that near all remnant hepatocytes underwent cell division after PHx, with the original liver mass being restored after one or two cell cycles. However, this was probably an oversimplified view, because it has been recently documented that the amount of resected liver really matters and triggers different proliferation stimuli. When two-thirds of the liver is removed, hypertrophy of the remnant liver occurs rapidly, followed by hyperplasia, with the entry into $S$ phase of almost all hepatocytes. In this context, binuclear hepatocytes undergo an unconventional cell division to cause two mononuclear daughter cells. In contrast, on one-third partial hepatectomy, the liver recovers its original mass mostly through hepatocyte hypertrophy alone, with few cell divisions and no modification of their ploidy ${ }^{9}$ (Figure 2).

Beyond a certain threshold of liver resection, the regenerative capacity of the remaining hepatocytes decreases, and liver failure occurs. In zebrafish, the almost complete ablation of the hepatocytes leads to the activation of biliary epithelial cells and their conversion into functional hepatocytes. ${ }^{10,11}$ This observation should be compared with an elegant experimental mouse model where, after $>98 \%$ of the resident hepatocytes were coaxed into senescence or apoptosis, progenitor cells from the biliary epithelial compartment contributed to a complete functional liver reconstitution. ${ }^{12}$ More recent experiments confirm these findings and show that p21 overexpression, in blocking hepatocyte proliferation, results in the significant emergence of hepatocytes derived from cholangiocytes. ${ }^{13}$ It thus appears that liver injury triggers different regenerative responses, such as hypertrophy, hyperplasia, or reprogramming of a specific cell compartment, depending on the size of the remaining liver mass (Figure 2).

Hepatic ischemia/reperfusion (I/R) injury is a major complication of large liver resection or of liver transplantation. In these situations, the early phase after reperfusion is characterized by macrophage activation and release of reactive oxygen species that triggers an inflammatory reaction leading 


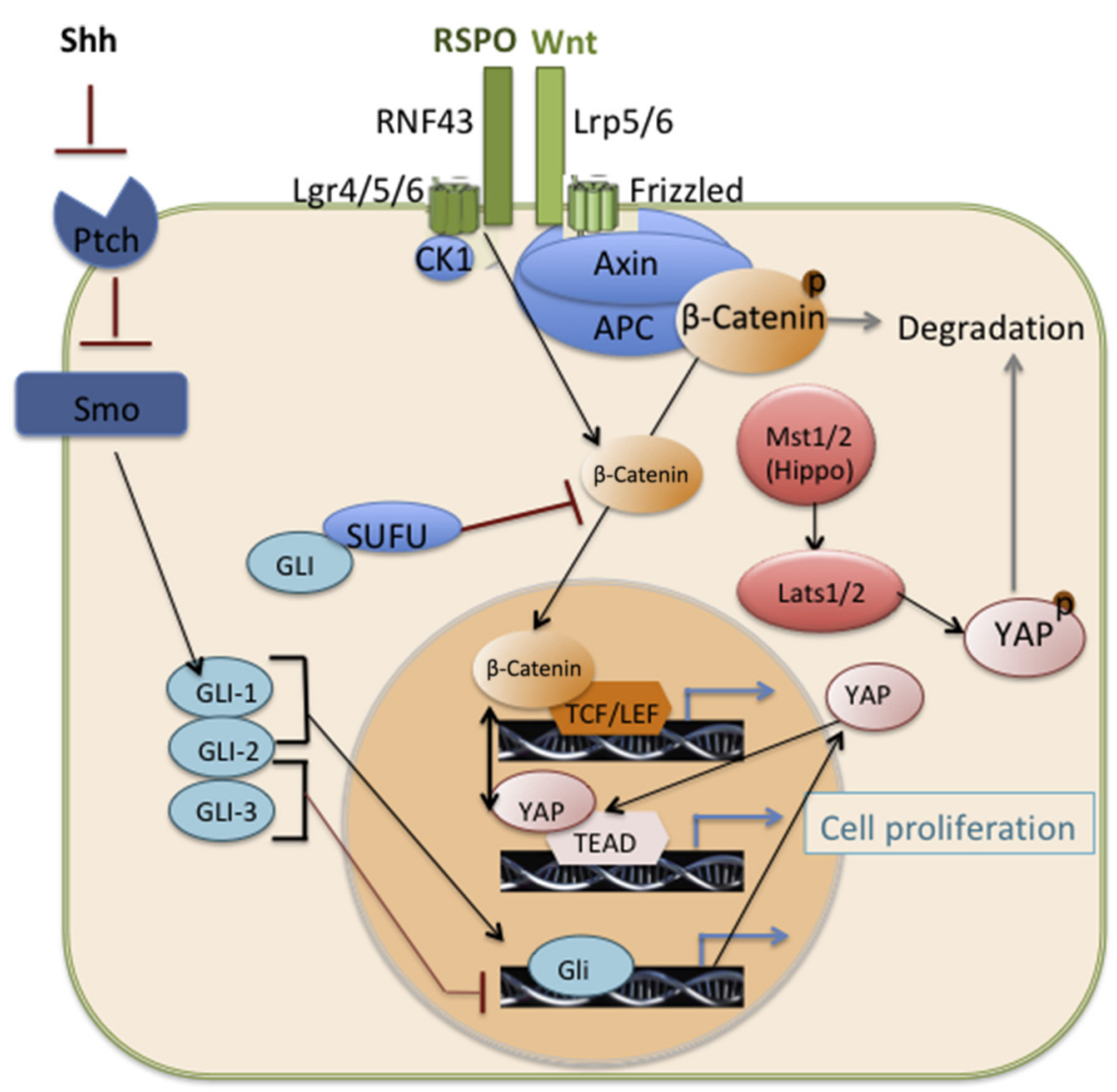

Figure 3 Wnt, Hedgehog, and Yes-associated protein (YAP) pathways cross talk in the hepatocyte. When Wnt binds to low-density lipoprotein receptor related 5 or $6($ Lrp5/6) protein and Frizzled receptors, the $\beta$-catenin degradation complex is recruited to the membrane, YAP is released in the cytoplasm, and $\beta$-catenin is no longer degraded. $\beta$ Catenin and YAP translocate into the nucleus, where they bind to lymphoid enhancer factor/T-cell factor (LEF/TCF) and transcriptional enhancer-associated domain (TEAD) factor, respectively, which, in turn, cooperate and activate their respective target genes. Ring finger 43 (RNF43) removes the Frizzled/Lrp receptors from the cell surface, resulting in their degradation. When R-spondin (RSPO) binds to its receptor leucine-rich repeat-containing G-proteincoupled (Lgr) $4 / 5 / 6$, it sequesters RNF43 and participates in the induction of $W n t / \beta$-catenin pathway. When Sonic hedgehog (Shh) binds to Patched (Ptch) receptor, it alleviates the inhibitory role on smoothened (Smo) receptor. Smo then activates glioma-associated oncogene (GLI) $1 / 2$ transcription factors. YAP is a downstream target of the Shh pathway, and GLI is a target of $\beta$-catenin/TCF4 activation. Altogether, the activation of these three pathways leads to hepatocyte proliferation. APC, adenomatosis polyposis coli; CK1, casein kinase 1 ; Lats, large tumor suppressor; Mst, mammalian sterile like or serine threonine kinase; SUFU, negative regulator of hedgehog signaling.

to liver injury. The late phase involves the recruitment of neutrophils that induces hepatocyte damage via oxidative stress and proteases. ${ }^{14}$ The trigger of liver regeneration after $\mathrm{I} / \mathrm{R}$ injury is not completely understood. However, although most of the mechanisms involved in liver regeneration after $\mathrm{PHx}$ are also operant after I/R, other pathways, such as NF- $\kappa \mathrm{B}$, provide not only a hepatoprotective effect but also a progenerative impact. ${ }^{15,16}$ Although inhibition of CXCR2 receptor reduces liver regeneration after PHx, it has opposite effects after I/R injury, where NF- $\kappa \mathrm{B}$ activation and hepatocyte proliferation are increased. Other differences between post-I/R regeneration and post-PHx regeneration involve the requirement to clear dead cells and the level of chemokines that is 10 to 20 times higher after I/R than after PHx. ${ }^{17}$ These high levels are supposed to induce a significant cytotoxicity, whereas they induce hepatocyte proliferation at lower concentrations. ${ }^{17}$

\section{Molecular Signaling Pathways Involved in Liver Regeneration}

We would like to underline herein the intertwined role of three molecular pathways in liver regeneration. The involvement of $\mathrm{Wnt} / \beta$-catenin signaling in regeneration has been documented in zebrafish, rodents, and humans. During the priming phase, in the early 5 minutes after PHx, $\beta$-catenin translocates to the hepatocyte nucleus and remains highly expressed during 24 hours. This increased nuclear localization of $\beta$-catenin participates in the induction of proliferative target genes, such as cyclin D1. Transgenic mice overexpressing liver-specific $\beta$-catenin show a hepatomegaly secondary to increased proliferation. In contrast, ablation of $\beta$-catenin transcription or liver $\beta$-catenin knockout delays liver regeneration after PHx. ${ }^{1,18}$ There is a complex cross talk between the $\beta$-catenin pathway and two growth factor receptor pathways that are essential for liver regeneration: c-Met and EGFR. When hepatocyte growth factor binds to its receptor, c-Met, it induces $\beta$-catenin phosphorylation and translocation to the nucleus. EGFR is also known as a transcriptional target of Wnt/ $\beta$-catenin signaling that may serve to prolong its mitogenic effects. $^{18}$ R-spondin ligands potentiate Wnt/ $\beta$-catenin signaling in binding to their leucine-rich repeat-containing G-protein-coupled 4/5 receptor and clearing the E3 ubiquitin ligases, zinc and ring finger 33 (ZNRF) and ring finger 43 (RNF43), that promote Wnt receptor turnover. ${ }^{6} \mathrm{R}$-spondin 1 injection accelerates liver regeneration, whereas $L g r 4 / 5$ deletion results in hypoplastic livers. Thus, the R-spondin-leucine-rich repeat-containing G-protein-coupled 4/5-ZNRF3/RNF43 axis is not only essential for functional Wnt/ $\beta$-catenin signaling, but it also acts as a rheostat controlling liver growth, size, and regeneration ${ }^{6}$ (Figure 3).

Among molecular signaling pathways contributing to liver regeneration, the Hippo/Yes-associated protein1 (Yap) pathway orchestrates liver homeostasis and hepatocytes' fate. ${ }^{19}$ Yap and its paralog WW domain containing 
transcription regulator 1 (alias TAZ) are downstream effectors of the Hippo pathway. In mammals, two upstream serine/ threonine kinases, Mst1/2 (Hippo homologs), phosphorylate Lats1/2 kinases that directly interact and phosphorylate Yap on serine 127. This leads to Yap cytoplasmic sequestration and proteosomal degradation. Because Yap does not have any DNA binding domain, it functions as a transcriptional coactivator of transcriptional enhancer-associated domain family members (Figure 3). Yap is barely detectable in healthy adult liver. However, its overexpression leads to liver overgrowth by increased hepatocyte proliferation. The rapid decrease in liver size after the restoration of endogenous Yap levels after a period of overexpression confirms that this pathway is essential for liver homeostasis. ${ }^{20}$ Interestingly, the search for small compounds selectively inhibiting Mst1/2 has led to the identification of a molecule, called XMU-MP1, that reversibly activates Yap and promotes mouse liver repair and regeneration in vivo after either an acute or a chronic liver injury. ${ }^{21}$ For the first time, a pharmacologic approach might thus help to support hepatocyte expansion after transplantation.

Yap and Wnt/ $\beta$-catenin pathways interact differently in various cell compartments. In the nucleus, Yap cooperates with $\beta$-catenin, whereas in the cytosol, Yap inhibits Wnt/ $\beta$-catenin activities. Moreover, the loss of Mst1/2 not only induces Yap activation but also $\mathrm{Wnt} / \beta$-catenin signaling in the liver. Interestingly, Yap is also a downstream effector of the Hedgehog pathway in the regenerating mouse liver. Both Hegdehog and Yap activities are increased in hepatocytes and hepatic stellate cells when the liver is stimulated to regenerate. ${ }^{22}$ Hedgehog signaling is critical for normal liver regeneration after partial hepatectomy. This pathway induces Gli target genes that are transcription factors known, once translocated into the nucleus, to regulate cellular proliferation, survival, and differentia$\operatorname{tion}^{23,24}$ (Figure 3). When hedgehog signaling is blocked in hepatic stellate cells (HSCs), there is no Yap accumulation in hepatocyte nuclei and hepatocyte proliferation is blunted, underlining the role of stromal cells in liver regeneration. However, further studies are required to understand how Wnt, Yap, and Hedgehog pathways interact, particularly in the context of various chronic liver injuries. It will also be important to define the role of WW domain containing transcription regulator 1 in liver regeneration and to determine the consequences of Yap/WW domain containing transcription regulator 1 zonation in liver homeostasis. In addition, more research is needed to fully define the signals regulating the Hippo core kinase cassette and especially to characterize mechanistically how Hippo/Yap integrates various and competing growth signals to regulate liver size.

Other pathways are also involved in liver regeneration. Because the liver has to face metabolic challenges and to maintain energy after a partial hepatectomy, phosphoinositide3 kinase/Akt/mammalian target of rapamycin signaling cascade is part of the answer for this metabolic demand. Consequently, deletion of a downstream effector of mammalian target of rapamycin, S6 protein, leads to an impaired DNA replication after $\mathrm{PHx} .{ }^{25}$

\section{New Insights into the Liver Regeneration Process}

Among factors released immediately after PHx, augmenter of liver regeneration has pleiotropic functions, among which are prosurvival functions, protecting hepatocytes from apoptosis and promoting growth functions equivalent to that of hepatocyte growth factor. ${ }^{26}$ Moreover, this cellular oxygen sensor is responsible for iron-sulfur cluster transfer and the stability of the mitochondrial outer membrane. The absence of hepatic augmenter of liver regeneration leads to the accumulation of triglycerides and cholesterol levels and has deleterious effects on liver regeneration. ${ }^{26}$ Bile acids (BAs) are also believed to influence liver regeneration. Hepatic resection leads to a drastic increase in the ratio of BAs/liver volume, overloading the remnant liver. This sudden increase has a negative impact on liver cells when in excess. However, BAs are also positively correlated with liver regenerative response. Any attempts to reduce the BA enterohepatic circulation have deleterious effects on liver regeneration after PHx. BAs act through receptors, particularly the farnesoid $\mathrm{X}$ receptor and the $\mathrm{G}$ protein-coupled bile acid receptor 5, and knockouts of both encoding genes in mice impair liver regeneration. ${ }^{27,28}$ Farnesoid $\mathrm{X}$ receptor is known to inhibit BA overproduction and to facilitate liver regeneration by upregulating a gut-secreted cytokine called fibroblast growth factor 15 in mice (fibroblast growth factor 19 in humans). ${ }^{22,29}$ Administration of fibroblast growth factor 19 has thus been proposed to promote regeneration in patients who require major liver resection. However, it is a double-edged sword because use of growth factors might induce uncontrolled proliferation. ${ }^{30}$

Some recent data also revisited the termination phase, uncovering the role of the CCAAT/enhancer binding protein (C/EBP). To study the epigenetic control of liver proliferation, the group of Timchenko ${ }^{31}$ generated an animal model that fails to stop liver regeneration after PHx. This model demonstrates that a proper cooperation between the CCAAT/ enhancer binding protein complex and the chromatin remodeling histone deacetylase 1 complex is essential for cessation of liver regeneration. ${ }^{31}$

A new actor recently entered the regeneration scene: the microbiota. There is a bidirectional dialogue in the so-called gut-liver axis between microbiota and BAs: gut microbiota regulate BA homeostasis, and BAs influence gut microbiota composition, ${ }^{32,33}$ because conjugated BAs exert antimicrobial effects in the digestive tract. How this permanent interplay affects precisely liver regeneration is not yet completely understood. However, as for BAs, it is all a question of balance: on the one hand, the release of bacterial endotoxins stimulates hepatocyte proliferation, but on the other hand a sustained dysbiosis impedes liver regeneration. These recent data open an interesting therapeutic window in the liver regeneration field, and a better understanding of the effects of probiotics on liver regeneration is expected in the near future. 


\section{The Origin, Fate, and Role of Liver Stem Cells in Liver Regeneration Are Still Controversial}

The presence of a stem cell pool in the normal liver has been the subject of controversy for $>60$ years. ${ }^{34}$ Peribiliary glands contain facultative stem cells that self-renew and differentiate into hepatocytes, cholangiocytes, and pancreatic islets. These glands are found in the human extrahepatic biliary tree, mostly near the hepatopancreatic ampulla and in intrahepatic bile ducts. ${ }^{35}$ Peribiliary gland cells contribute to replacement of cholangiocytes in chronic bile duct injuries, such as primary sclerosing cholangitis. ${ }^{36}$ In normal human adult liver, liver progenitor cells (LPCs) are found in the vicinity of the canal of Hering and exhibit bipotential differentiation capacity into both hepatocytes and cholangiocytes. ${ }^{37,38}$ Whether these cells participate in liver regeneration is still debated, with some studies arguing against their contribution, ${ }^{39}$ whereas others suggest that they play a small, yet significant, role. ${ }^{40,41}$ Nevertheless, primary human bile duct cells have been obtained from healthy human donor liver biopsy specimens and expanded in vitro into three-dimensional organoids. These cells preserve their genetic stability on long-term culture and differentiate into functional hepatocytes both in vitro and in vivo. ${ }^{42}$

In rodents, LPCs are mainly detected when the liver is injured and hepatocyte proliferation capacity is exhausted. The paradigmatic model for progenitor cell induction in rats (commonly called oval cells in rodents) has long been the administration of 2-acetylaminofluorene, which blocks hepatocyte proliferation, associated with PHx. In mice, dietinduced liver injury (namely, choline-deficient ethionine supplemented diet or administration of diethoxycarbonyl1,4-dihydrocollidine diet) has been extensively used to determine the origin of LPCs. Using these models, Malato et $\mathrm{al}^{43}$ first demonstrated that all newly formed hepatocytes after injury derived from preexisting hepatocytes. Interestingly, numerous subsequent articles, based on lineage tracing studies in mouse models of diet-induced chronic liver injury, corroborate the claims that LPCs originated from dedifferentiating mature hepatocytes, ${ }^{39,44,45}$ generating numerous comments in the literature. ${ }^{38,46,47}$ However, some controversies remain. These discrepancies could be because of major differences induced by the various models of liver injuries (eg, 2-acetylaminofluorene forms DNA adducts, diethoxycarbonyl-1,4-dihydrocollidine diet induces cholangiocyte injury, whereas choline-deficient ethionine supplemented diet induces hepatocyte injury and triglyceride accumulation). It is not yet known whether the dedifferentiation ability belongs to all mature hepatocytes or is limited to a specific subset of cells, such as the above mentioned hybrid hepatocytes. The ongoing debate on the contribution of stem cells in liver regeneration has been compared with the parable of the blind men and the elephant, ${ }^{48}$ meaning that we still need to take a step back and carefully compare the performed experiments to see the entirety of the data. The use of clinically irrelevant choline-deficient ethionine supplemented diet and diethoxycarbonyl-1,4-dihydrocollidine diet mouse models of chronic liver injury, as well as the variable and difficult choice of suitable LPC markers (leucine-rich repeat-containing G-protein-coupled receptor 5, osteopontin, forkhead box L1, epithelial cell adhesion molecule, and sex determining region Y-box 9), has confounded our understanding of the origin(s) of stem cells and their role(s) in liver regeneration. We might, however, underline the fact that the induction of senescence in near all mouse hepatocytes has been, until now, the only way to restore liver architecture and function from progenitor cells. ${ }^{18}$

Determining which signaling pathways are involved in hepatocytes' ability to dedifferentiate into LPCs could lead to ways to promote hepatocyte plasticity. YAP signaling appears to be, once again, a good candidate because YAP ectopic expression in mature hepatocytes transforms these epithelial cells into progenitor cells. These LPCs are able to proliferate and to differentiate into hepatocytes. More interestingly, the conversion of rat or mouse fully differentiated hepatocytes into bipotent progenitor cells has been obtained with a mixture of three small molecules that target Rho kinase, transforming growth factor- $\beta$, and glycogen synthase kinase 3 pathways, offering a pharmacologic approach for plasticity. Moreover, these chemically induced liver progenitors differentiate into both mature hepatocytes and biliary cells and repopulate efficiently a rodent liver. ${ }^{49}$ Unfortunately, this approach has been unsuccessful until now with human hepatocytes.

Wnt, Notch, and fibroblast growth factor pathways are essential for LPC activation and differentiation. ${ }^{50,51}$ More important, the type of injury modulates the fate of these progenitor cells, whatever their origin might be. During chronic biliary injury, the expression of a Notch ligand by myofibroblasts induces the specification of LPCs to cholangiocytes. ${ }^{50}$ In contrast, hepatocyte injury will favor the induction of the Wnt pathway and the activation of the Notch inhibitor Numb, guiding LPCs toward a hepatocyte fate. ${ }^{50}$ Hedgehog ligands also play a key role, both directly and indirectly, in recruiting macrophages that modulate LPC differentiation into hepatocytes. ${ }^{51}$

Thus, the current view is that plasticity is the dominant feature of the hepatocytes. These epithelial cells can become LPCs, although it is not known whether all hepatocytes or a limited proportion of them are prone to do so. Indeed, it will be interesting to determine whether hepatocytes with stem cell properties located at each pole of the lobule also have higher plasticity properties. However, we have to keep in mind that mouse models do not recapitulate human liver diseases, particularly because human hepatocytes reach senescence in chronic injury, whereas mouse hepatocytes do not.

\section{Liver Regeneration Defects in Human Chronic Liver Diseases (Fibrosis and Steatosis)}

Although PHx has provided essential information on the liver regeneration process, it does not reflect the various 
human liver diseases that decrease liver function and would be expected to modulate regeneration. In PHx, the remnant liver is uninjured, whereas in chronic liver diseases, there is usually diffuse inflammation and hepatocyte death. Moreover, a common feature of all chronic liver diseases is progression to fibrosis, characterized by increased production of matrix proteins, mainly induced by activated HSCs and decreased matrix remodeling. An increase in the proportion of senescent hepatocytes (ie, hepatocytes arrested at $\mathrm{G}_{1} / \mathrm{S}$ transition of the cell cycle) is observed with fibrosis. Furthermore, the rate of hepatocyte telomere shortening, which hampers cell division, has been shown to correlate with the rate of fibrosis progression. ${ }^{52}$ Altogether, these data support the notion that liver fibrosis progression is associated with liver regeneration impairment. In addition, several pathways, such as Hippo/YAP, are involved in both liver regeneration and HSC activation, underlining the complex balance between regeneration and fibrosis.

Hepatocyte proliferation defects are also observed in fatty liver disease that is often associated with diabetes and obesity and is free of fibrosis in its early stages. Patients with nonalcoholic fatty liver disease or nonalcoholic steatohepatitis, the prevalence rate of which is estimated approximately $40 \%$ in Western countries, show a higher incidence of complications and mortality after liver surgery. ${ }^{53,54}$ Using computed tomography, it has been shown that liver steatosis-defined by hepatocyte triglycerides accumulation-is correlated with volumetric liver recovery defects, suggesting regeneration impairment. ${ }^{55}$ Hepatocyte proliferation is impaired in experimental rodent models of steatosis, whatever is the degree of fibrosis extension. Different mechanisms have been proposed to explain these liver regeneration defects in nonalcoholic fatty liver disease, such as an exacerbation of cytokine production ${ }^{56}$ or a deficiency in the EGFR pathway. ${ }^{57}$ Interestingly, the administration of growth hormone to obese mice with steatosis partially rescues the hepatocyte proliferation delay. ${ }^{57}$ However, hepatocytes from nonalcoholic fatty liver disease mice do not progress through the cell cycle. This block is because of abnormal oxidative stress. When hepatocytes with steatosis are treated with an antioxidant, they restore a normal cell cycle and normalize their physiological state of polyploidy. ${ }^{58}$ Interestingly, growth arrest and DNA damage-inducible 34, a factor known to regulate the integrated stress response, is capable of promoting hepatic regeneration of a fatty liver. Enhanced integrated stress response is responsible for hepatocyte apoptosis and impaired regeneration of a liver with steatosis, and growth arrest and DNA damage-inducible 34-enhanced activity reduces both impaired regeneration of fatty liver and hepatocyte apoptosis. It could thus constitute a novel therapeutic target for impaired regeneration in hepatic steatosis. ${ }^{59}$ Finally, the negative impact of steatosis on liver regeneration may also be explained by a dysbiosis, particularly a decrease in microbial diversity, such as Bifidobacterium, observed in obese and nonalcoholic steatohepatitis patients.

Whatever the etiology of chronic liver disease, a ductular reaction, composed of differentiated cells and LPCs in a complex extracellular matrix containing inflammatory cells, endothelial cells, and mesenchymal cells, appears in the periportal region of chronically injured livers. ${ }^{60}$ These LPCs are heterogeneous, some of them expressing biliary markers, hepatoblast markers, and/or stem cell markers. ${ }^{45}$ They have the capacity to differentiate into hepatocytes and biliary cells in vitro and to form hepatocyte buds, repopulating the damaged parenchyma in specific situations in vivo. ${ }^{61}$ However, their ability to participate in liver regeneration in different human settings is far from clear. ${ }^{46,48}$ Conversely, an increased fibrogenic response has been correlated with the activation of LPCs in chronically injured livers. ${ }^{62-64}$ In chronic hepatitis, the dialogue between LPCs and HSCs plays a key role in the fibrogenic process. HSCs secrete numerous growth factors, among which hepatocyte growth factor promotes not only hepatocyte but also LPC proliferation. On the other hand, LPCs recruit activated HSCs by expressing monocyte chemoattractant protein 1 and platelet-derived growth factor- $\beta$, favoring fibrosis. In patients with alcoholic hepatitis, it has been shown that LPCs are inefficient in generating mature hepatocytes. ${ }^{65}$ Moreover, the expansion of LPCs is positively correlated with the severity of the liver disease and short-term mortality ${ }^{66}$ Finally, this ductular reaction is correlated with tumor recurrence after hepatocellular carcinoma resection. ${ }^{67}$ Altogether, these observations, added to the fact that LPCs have a lower repopulating activity than hepatocytes themselves, limit the interest in the capacity of these cells to repopulate a chronically injured liver in a therapeutic prospect.

\section{Applications in Liver Regenerative Medicine}

\section{Liver Repopulation by Cell Transplantation}

Regenerative medicine approaches have taken advantage of the liver's unique regenerative ability for decades. The most common therapeutic option for patients with end-stage liver diseases is liver transplantation. However, regeneration by repopulation with transplanted hepatocytes has been explored as an alternative regenerative approach for patients with liver-based inborn errors of metabolism or acute liver failure. ${ }^{68,69}$ Clinical trials have proved that injecting primary hepatocytes through the portal vein is a safe and effective procedure, but only leads to a short-term partial correction of metabolic disorders. ${ }^{70}$ To be an effective regenerative therapy, engraftment and proliferation need to be optimized. To this end, several studies have focused their efforts on inducing a strong liver regenerative stimulus and giving a proliferative advantage to the donor cells with various preconditioning techniques involving partial hepatectomy, ${ }^{71}$ portal embolization, ${ }^{72}$ partial host liver irradiation, ${ }^{73}$ and repeated cell transplantation ${ }^{74}$ (Figure 4).

One of the main hurdles, besides the still poor effectiveness of the procedure, relies in the difficulty in obtaining an easy and reproducible hepatocyte source. Primary hepatocytes survive poorly in hypothermic storage conditions 


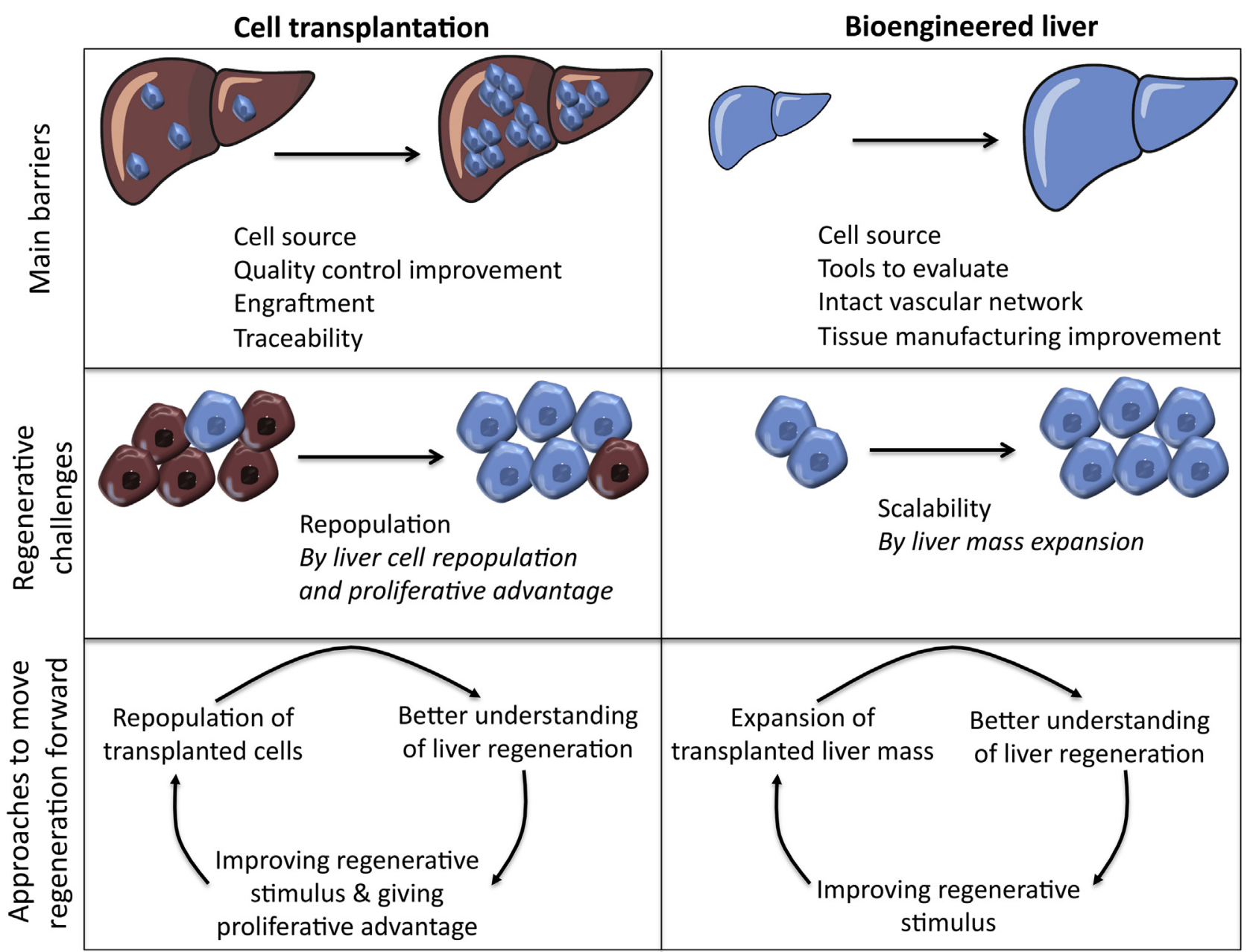

Figure 4 The challenges of liver regenerative medicine. Hepatocyte transplantation and liver bioengineering face major barriers before being applicable to clinic, such as the choice of the best cell source for both approaches, engraftment efficiency, proper tools to evaluate rejection episodes for the former, how to monitor the graft functions, generating an intact vascular network, and improving tissue manufacturing techniques for the latter. In addition, both approaches face the hurdle of effective hepatic regeneration. Transplanted cells need to proliferate to repopulate a liver, and bioengineered livers have to grow after surgery to reach human liver size. A better understanding in the mechanisms governing liver regeneration in vivo will help to offer new perspectives and to improve liver regenerative medicine approaches. Conversely, efficient liver regenerative medicine techniques will yield new understanding of liver regeneration mechanisms.

and vary in number, availability, and quality. There is a lack of quality control evaluation pretransplantation and a poor traceability of cells post-transplantation, making it difficult to monitor the cell's repopulation ability and function and to track rejection episodes over time (Figure 4). Other cell sources have been investigated, such as bone marrow-derived mesenchymal stem cells, hematopoietic stem cells, and LPCs. Finally, with the advent of human induced pluripotent stem cells (hiPSCs), it has become conceivable to generate an ideal, high-quality, and unlimited liver cell source, challenging the current standard for immunosuppression. ${ }^{75,76}$

Espejel et $\mathrm{al}^{77}$ provided a proof of principle that hiPSCs can repopulate a liver, with normal functionality and unique proliferative capabilities. The group injected normal mouse induced pluripotent stem cells into blastocysts of fumarylacetoacetate hydrolase-deficient mice. This mouse model of hereditary tyrosinemia type I is a liver injury model that relies on the presence of 2-(2-nitro-4-fluoromethylbenzoyl)1,3-cyclohexanedione (NTBC) for survival. On NTBC withdrawal, cells derived from the transplanted wild-type induced pluripotent stem cells are able to reconstitute the liver of fumarylacetoacetate hydrolase-deficient mice by differentiating into fully mature hepatocytes. Interestingly, these hepatocytes displayed normal liver regeneration abilities after a subsequent PHx. hiPSCs need to undergo in vitro differentiation into hepatocytes before transplantation. Current protocols to differentiate hiPSCs into hepatocytes have failed to provide highly functional hepatocytes with the potential to regenerate.

Huang et $\mathrm{al}^{78}$ have shown the feasibility to induce hepatocytes by directly reprogramming mouse fibroblasts with three transcription factors (Gata4, Foxa3, and Hnf1) and by inactivating $\mathrm{p} 19^{\mathrm{ARF}}$. This was also performed on human fibroblasts. ${ }^{79}$ Another study focused on inducing hepatic stem cells by reprogramming mouse fibroblasts 
using Hnf1 $\beta$ and Foxa3 transcription factors. ${ }^{79}$ Transplantation of induced hepatocytes into rodent models using such cells has shown low to moderate repopulation ability. ${ }^{78-83}$ Although these studies are important milestones in regenerative medicine, several hurdles remain to be overcome. Direct reprogramming can result in incomplete reprogramming, and hepatic differentiation protocols still do not cause complete mature hepatocytes with a strong regenerative potential. However, continued improvement in the understanding of molecular pathways governing liver regeneration as well as better-quality hiPSC-derived technologies will surely solve the problem within the next decade.

\section{Liver Bioengineering}

Considering that a large number of cells are lost with cell transplantation (rejection episodes, apoptosis, and engraftment failure) and that end-stage liver diseases are incompatible with cell therapy because of the lack of an appropriate environment for cell engraftment and repopulation (fibrosis and cirrhosis), different lines of research investigate solutions to regenerate a liver from scratch.

There are essentially three promising approaches to regenerate a liver: whole organ assembly, liver organoid formation, and three-dimensional bioprinting of liver tissue. ${ }^{84}$ The innate ability of the liver to regenerate and the extensive interest in regenerative medicine ensure genuine progress is being made in this field. ${ }^{85,86}$ However, these techniques are several steps away from clinical application and face issues of cell sources, tools available to evaluate organ function, and size restriction for scaling up (Figure 4). In addition, even if it is possible to grow liver tissue in vitro, the main challenges remain after surgery. For transplantation, approximately $30 \%$ of liver mass is needed; it is essential to demonstrate that bioengineered livers are clinically safe, the vasculature network is intact to allow a functional vascularization, and the organ has regenerative capacities. To that end, Stevens et $\mathrm{al}^{86}$ recently showed a 50-fold expansion of structurally organized engineered liver tissue in response to regenerative stimulus in vivo. The group generated liver tissue with human hepatocytes, endothelial cells, and stromal cells patterned in a degradable hydrogel and evaluated the tissue over an 11-week period after ectopic implantation in fumarylacetoacetate hydrolase-deficient, nonobese diabetic, recombinase activating gene-deficient and IL-2 receptor $\gamma$ chain-deficient mice. As explained above, recombinase activating gene-deficient and IL-2 receptor $\gamma$ chain-deficient mice need to be treated with NTBC to avoid liver failure. Animals treated by cycles of NTBC withdrawal to cause liver injury and regenerative stimulus have larger hepatic grafts than the ones who remained under NTBC at all times. Grafts are positive for proliferative markers and show a higher mRNA expression of genes known to induce hepatic proliferation. This work provides a proof of principle that engineered liver tissue can adopt hepatic regenerative properties in response to proliferative cues.

\section{Conclusions}

The unique regenerative abilities of the liver have been a highly motivating subject of research for several decades. First, understanding liver regeneration could unlock mechanisms of regeneration on other organs. Second, it has important clinical applications, ranging from large liver resections, to acute liver failure, to living-donor liver transplantation. Third, liver regenerative abilities help the field of regenerative medicine to move forward substantially. Indeed, regardless of whether this can be achieved by cell therapy treatment or by regrowing an entire new liver, a better understanding of liver regeneration is essential to propose treatments for liver regenerative medicine. Conversely, regenerative medicine may help us decipher mechanisms governing liver regeneration. Humanized models of liver tissue originated from regenerative medicine approaches would be a substantive departure from the traditional methods of studying liver regeneration in animal models and may help us to shed new light on this phenomenon. Eventually, with constant new discoveries and lines of research involving liver regeneration, the field surely has bright days ahead of it.

\section{Supplemental Data}

Supplemental material for this article can be found at https://doi.org/10.1016/j.ajpath.2018.03.008.

\section{References}

1. Michalopoulos GK: Hepatostat: liver regeneration and normal liver tissue maintenance. Hepatology 2017, 65:1384-1392

2. Gilgenkrantz H, Collin de l'Hortet A: New insights into liver regeneration. Clin Res Hepatol Gastroenterol 2011, 35:623-629

3. Paranjpe S, Bowen WC, Mars WM, Orr A, Haynes MM, DeFrances MC, Liu S, Tseng GC, Tsagianni A, Michalopoulos GK: Combined systemic elimination of MET and epidermal growth factor receptor signaling completely abolishes liver regeneration and leads to liver decompensation. Hepatology 2016, 64:1711-1724

4. Wang B, Zhao L, Fish M, Logan CY, Nusse R: Self-renewing diploid Axin2(+) cells fuel homeostatic renewal of the liver. Nature 2015, 524:180-185

5. Font-Burgada J, Shalapour S, Ramaswamy S, Hsueh B, Rossell D, Umemura A, Taniguchi K, Nakagawa H, Valasek MA, Ye L, Kopp JL, Sander M, Carter H, Deisseroth K, Verma IM, Karin M: Hybrid periportal hepatocytes regenerate the injured liver without giving rise to cancer. Cell 2015, 162:766-779

6. Planas-Paz L, Orsini V, Boulter L, Calabrese D, Pikiolek M, Nigsch F, Xie Y, Roma G, Donovan A, Marti P, Beckmann N, Dill MT, Carbone W, Bergling S, Isken A, Mueller M, Kinzel B, Yang Y, Mao X, Nicholson TB, Zamponi R, Capodieci P, Valdez R, Rivera D, Loew A, Ukomadu C, Terracciano LM, Bouwmeester T, Cong F, Heim MH, Forbes SJ, Ruffner H, Tchorz JS: The RSPOLGR4/5-ZNRF3/RNF43 module controls liver zonation and size. Nat Cell Biol 2016, 18:467-479

7. Pu W, Zhang H, Huang X, Tian X, He L, Wang Y, Zhang L, Liu Q, Li Y, Li Y, Zhao H, Liu K, Lu J, Zhou Y, Huang P, Nie Y, Yan Y, Hui L, Lui KO, Zhou B: Mfsd2a+ hepatocytes repopulate the liver during injury and regeneration. Nat Commun 2016, 7:13369 
8. Ding BS, Nolan DJ, Butler JM, James D, Babazadeh AO, Rosenwaks Z, Mittal V, Kobayashi H, Shido K, Lyden D, Sato TN, Rabbany SY, Rafii S: Inductive angiocrine signals from sinusoidal endothelium are required for liver regeneration. Nature 2010, 468:310-315

9. Miyaoka Y, Ebato K, Kato H, Arakawa S, Shimizu S, Miyajima A: Hypertrophy and unconventional cell division of hepatocytes underlie liver regeneration. Curr Biol 2012, 22:1166-1175

10. Choi TY, Ninov N, Stainier DY, Shin D: Extensive conversion of hepatic biliary epithelial cells to hepatocytes after near total loss of hepatocytes in zebrafish. Gastroenterology 2014, 146:776-788

11. He J, Lu H, Zou Q, Luo L: Regeneration of liver after extreme hepatocyte loss occurs mainly via biliary transdifferentiation in zebrafish. Gastroenterology 2014, 146:789-800.e8

12. Lu WY, Bird TG, Boulter L, Tsuchiya A, Cole AM, Hay T, Guest RV, Wojtacha D, Man TY, Mackinnon A, Ridgway RA, Kendall T, Williams MJ, Jamieson T, Raven A, Hay DC, Iredale JP, Clarke AR, Sansom OJ, Forbes SJ: Hepatic progenitor cells of biliary origin with liver repopulation capacity. Nat Cell Biol 2015, 17:971-983

13. Raven A, Lu WY, Man TY, Ferreira-Gonzalez S, O’Duibhir E, Dwyer BJ, Thomson JP, Meehan RR, Bogorad R, Koteliansky V, Kotelevtsev Y, Ffrench-Constant C, Boulter L, Forbes SJ: Cholangiocytes act as facultative liver stem cells during impaired hepatocyte regeneration. Nature 2017, 547:350-354

14. Konishi T, Lentsch AB: Hepatic ischemia/reperfusion: mechanisms of tissue injury, repair, and regeneration. Gene Expr 2017, 17: $277-287$

15. Iimuro Y, Nishiura T, Hellerbrand C, Behrns KE, Schoonhoven R, Grisham JW, Brenner DA: NFkappaB prevents apoptosis and liver dysfunction during liver regeneration. J Clin Invest 1998, 101:802-811

16. $\mathrm{Xu} \mathrm{Y}$, Bialik $\mathrm{S}$, Jones BE, limuro $\mathrm{Y}$, Kitsis RN, Srinivasan A, Brenner DA, Czaja MJ: NF-kappaB inactivation converts a hepatocyte cell line TNF-alpha response from proliferation to apoptosis. Am J Physiol 1998, 275:C1058-C1066

17. Kuboki S, Shin T, Huber N, Eismann T, Galloway E, Schuster R, Blanchard J, Edwards MJ, Lentsch AB: Hepatocyte signaling through CXC chemokine receptor-2 is detrimental to liver recovery after ischemia/reperfusion in mice. Hepatology 2008, 48:1213-1223

18. Nejak-Bowen KN, Monga SP: Beta-catenin signaling, liver regeneration and hepatocellular cancer: sorting the good from the bad. Semin Cancer Biol 2011, 21:44-58

19. Yimlamai D, Christodoulou C, Galli GG, Yanger K, Pepe-Mooney B, Gurung B, Shrestha K, Cahan P, Stanger BZ, Camargo FD: Hippo pathway activity influences liver cell fate. Cell 2014, 157:1324-1338

20. Patel SH, Camargo FD, Yimlamai D: Hippo signaling in the liver regulates organ size, cell fate, and carcinogenesis. Gastroenterology 2017, 152:533-545

21. Fan F, He Z, Kong LL, Chen Q, Yuan Q, Zhang S, Ye J, Liu H, Sun X, Geng J, Yuan L, Hong L, Xiao C, Zhang W, Sun X, Li Y, Wang P, Huang L, Wu X, Ji Z, Wu Q, Xia NS, Gray NS, Chen L, Yun CH, Deng X, Zhou D: Pharmacological targeting of kinases MST1 and MST2 augments tissue repair and regeneration. Sci Transl Med 2016, 8:352ra108

22. Zhang L, Wang YD, Chen WD, Wang X, Lou G, Liu N, Lin M, Forman BM, Huang W: Promotion of liver regeneration/repair by farnesoid $\mathrm{X}$ receptor in both liver and intestine in mice. Hepatology $2012,56: 2336-2343$

23. Swiderska-Syn M, Xie G, Michelotti GA, Jewell ML, Premont RT, Syn WK, Diehl AM: Hedgehog regulates yes-associated protein 1 in regenerating mouse liver. Hepatology 2016, 64:232-244

24. Ochoa B, Syn WK, Delgado I, Karaca GF, Jung Y, Wang J, Zubiaga AM, Fresnedo O, Omenetti A, Zdanowicz M, Choi SS, Diehl AM: Hedgehog signaling is critical for normal liver regeneration after partial hepatectomy in mice. Hepatology 2010, 51:1712-1723

25. Volarevic S, Stewart MJ, Ledermann B, Zilberman F, Terracciano L, Montini E, Grompe M, Kozma SC, Thomas G: Proliferation, but not growth, blocked by conditional deletion of 40S ribosomal protein S6. Science 2000, 288:2045-2047
26. Gandhi CR, Chaillet JR, Nalesnik MA, Kumar S, Dangi A, Demetris AJ, Ferrell R, Wu T, Divanovic S, Stankeiwicz T, Shaffer B, Stolz DB, Harvey SA, Wang J, Starzl TE: Liver-specific deletion of augmenter of liver regeneration accelerates development of steatohepatitis and hepatocellular carcinoma in mice. Gastroenterology 2015, 148:379-391.e4

27. Pean N, Doignon I, Garcin I, Besnard A, Julien B, Liu B, Branchereau S, Spraul A, Guettier C, Humbert L, Schoonjans K, Rainteau D, Tordjmann T: The receptor TGR5 protects the liver from bile acid overload during liver regeneration in mice. Hepatology 2013, 58:1451-1460

28. Gilgenkrantz H, Tordjmann T: Bile acids and FGF receptors: orchestrators of optimal liver regeneration. Gut 2015, 64:1351-1352

29. Padrissa-Altes S, Bachofner M, Bogorad RL, Pohlmeier L, Rossolini T, Bohm F, Liebisch G, Hellerbrand C, Koteliansky V, Speicher T, Werner S: Control of hepatocyte proliferation and survival by Fgf receptors is essential for liver regeneration in mice. Gut $2015,64: 1444-1453$

30. Uriarte I, Fernandez-Barrena MG, Monte MJ, Latasa MU, Chang HC, Carotti S, Vespasiani-Gentilucci U, Morini S, Vicente E, Concepcion AR, Medina JF, Marin JJ, Berasain C, Prieto J, Avila MA: Identification of fibroblast growth factor 15 as a novel mediator of liver regeneration and its application in the prevention of post-resection liver failure in mice. Gut 2013, 62:899-910

31. Jin J, Hong IH, Lewis $\mathrm{K}$, Iakova $\mathrm{P}$, Breaux $\mathrm{M}$, Jiang $\mathrm{Y}$, Sullivan E, Jawanmardi N, Timchenko L, Timchenko NA: Cooperation of $\mathrm{C} / \mathrm{EBP}$ family proteins and chromatin remodeling proteins is essential for termination of liver regeneration. Hepatology 2015, 61:315-325

32. Liu HX, Keane R, Sheng L, Wan YJ: Implications of microbiota and bile acid in liver injury and regeneration. J Hepatol 2015, 63: $1502-1510$

33. Wahlstrom A, Sayin SI, Marschall HU, Backhed F: Intestinal crosstalk between bile acids and microbiota and its impact on host metabolism. Cell Metab 2016, 24:41-50

34. Itoh T: Stem/progenitor cells in liver regeneration. Hepatology 2016, 64:663-668

35. Lanzoni G, Cardinale V, Carpino G: The hepatic, biliary, and pancreatic network of stem/progenitor cell niches in humans: a new reference frame for disease and regeneration. Hepatology 2016, 64: 277-286

36. Carpino G, Cardinale V, Renzi A, Hov JR, Berloco PB, Rossi M, Karlsen TH, Alvaro D, Gaudio E: Activation of biliary tree stem cells within peribiliary glands in primary sclerosing cholangitis. J Hepatol 2015, 63:1220-1228

37. Miyajima A, Tanaka M, Itoh T: Stem/progenitor cells in liver development, homeostasis, regeneration, and reprogramming. Cell Stem Cell 2014, 14:561-574

38. Lukacs-Kornek V, Lammert F: The progenitor cell dilemma: cellular and functional heterogeneity in assistance or escalation of liver injury. J Hepatol 2017, 66:619-630

39. Tarlow BD, Pelz C, Naugler WE, Wakefield L, Wilson EM, Finegold MJ, Grompe M: Bipotential adult liver progenitors are derived from chronically injured mature hepatocytes. Cell Stem Cell 2014, 15:605-618

40. Espanol-Suner R, Carpentier R, Van Hul N, Legry V, Achouri Y, Cordi S, Jacquemin P, Lemaigre F, Leclercq IA: Liver progenitor cells yield functional hepatocytes in response to chronic liver injury in mice. Gastroenterology 2012, 143:1564-1575.e7

41. Shin S, Upadhyay N, Greenbaum LE, Kaestner KH: Ablation of Foxl1-Cre-labeled hepatic progenitor cells and their descendants impairs recovery of mice from liver injury. Gastroenterology 2015, 148:192-202.e3

42. Huch M, Gehart $H$, van Boxtel $R$, Hamer $K$, Blokzijl F, Verstegen MM, Ellis E, van Wenum M, Fuchs SA, de Ligt J, van de Wetering M, Sasaki N, Boers SJ, Kemperman H, de Jonge J, Ijzermans JN, Nieuwenhuis EE, Hoekstra R, Strom S, Vries RR, van 
der Laan LJ, Cuppen E, Clevers H: Long-term culture of genomestable bipotent stem cells from adult human liver. Cell 2015, 160: 299-312

43. Malato Y, Naqvi S, Schurmann N, Ng R, Wang B, Zape J, Kay MA, Grimm D, Willenbring $\mathrm{H}$ : Fate tracing of mature hepatocytes in mouse liver homeostasis and regeneration. J Clin Invest 2011, 121: 4850-4860

44. Yanger K, Knigin D, Zong Y, Maggs L, Gu G, Akiyama H, Pikarsky E, Stanger BZ: Adult hepatocytes are generated by selfduplication rather than stem cell differentiation. Cell Stem Cell 2014, 15:340-349

45. Schaub JR, Malato Y, Gormond C, Willenbring H: Evidence against a stem cell origin of new hepatocytes in a common mouse model of chronic liver injury. Cell Rep 2014, 8:933-939

46. Kaur S, Siddiqui H, Bhat MH: Hepatic progenitor cells in action: liver regeneration or fibrosis? Am J Pathol 2015, 185:2342-2350

47. Forbes SJ, Newsome PN: Liver regeneration: mechanisms and models to clinical application. Nat Rev Gastroenterol Hepatol 2016, $13: 473-485$

48. Reid LM: Paradoxes in studies of liver regeneration: relevance of the parable of the blind men and the elephant. Hepatology 2015, 62: 330-333

49. Katsuda T, Kawamata M, Hagiwara K, Takahashi RU, Yamamoto Y, Camargo FD, Ochiya T: Conversion of terminally committed hepatocytes to culturable bipotent progenitor cells with regenerative capacity. Cell Stem Cell 2017, 20:41-55

50. Boulter L, Govaere O, Bird TG, Radulescu S, Ramachandran P, Pellicoro A, Ridgway RA, Seo SS, Spee B, Van Rooijen N, Sansom OJ, Iredale JP, Lowell S, Roskams T, Forbes SJ: Macrophage-derived Wnt opposes Notch signaling to specify hepatic progenitor cell fate in chronic liver disease. Nat Med 2012, $18: 572-579$

51. Kwon H, Song K, Han C, Chen W, Wang Y, Dash S, Lim K, Wu T: Inhibition of hedgehog signaling ameliorates hepatic inflammation in mice with nonalcoholic fatty liver disease. Hepatology 2016, 63: $1155-1169$

52. Aravinthan A, Scarpini C, Tachtatzis P, Verma S, Penrhyn-Lowe S, Harvey R, Davies SE, Allison M, Coleman N, Alexander G: Hepatocyte senescence predicts progression in non-alcohol-related fatty liver disease. J Hepatol 2013, 58:549-556

53. Gomez D, Malik HZ, Bonney GK, Wong V, Toogood GJ, Lodge JP, Prasad KR: Steatosis predicts postoperative morbidity following hepatic resection for colorectal metastasis. Br J Surg 2007, 94: $1395-1402$

54. Kele PG, van der Jagt EJ, Gouw AS, Lisman T, Porte RJ, de Boer MT: The impact of hepatic steatosis on liver regeneration after partial hepatectomy. Liver Int 2013, 33:469-475

55. Truant S, Bouras AF, Petrovai G, Buob D, Ernst O, Boleslawski E, Hebbar M, Pruvot FR: Volumetric gain of the liver after major hepatectomy in obese patients: a case-matched study in 84 patients. Ann Surg 2013, 258:696-702; discussion 702-704

56. Leclercq IA, Field J, Farrell GC: Leptin-specific mechanisms for impaired liver regeneration in ob/ob mice after toxic injury. Gastroenterology 2003, 124:1451-1464

57. Collin de l'Hortet A, Zerrad-Saadi A, Prip-Buus C, Fauveau V, Helmy N, Ziol M, Vons C, Billot K, Baud V, Gilgenkrantz H, Guidotti JE: GH administration rescues fatty liver regeneration impairment by restoring GH/EGFR pathway deficiency. Endocrinology 2014, 155:2545-2554

58. Gentric G, Maillet V, Paradis V, Couton D, L'Hermitte A, Panasyuk G, Fromenty B, Celton-Morizur S, Desdouets C: Oxidative stress promotes pathologic polyploidization in nonalcoholic fatty liver disease. J Clin Invest 2015, 125:981-992

59. Inaba Y, Furutani T, Kimura K, Watanabe H, Haga S, Kido Y, Matsumoto M, Yamamoto Y, Harada K, Kaneko S, Oyadomari S, Ozaki M, Kasuga M, Inoue H: Growth arrest and DNA damage- inducible 34 regulates liver regeneration in hepatic steatosis in mice. Hepatology 2015, 61:1343-1356

60. Gouw AS, Clouston AD, Theise ND: Ductular reactions in human liver: diversity at the interface. Hepatology 2011, 54:1853-1863

61. Stueck AE, Wanless IR: Hepatocyte buds derived from progenitor cells repopulate regions of parenchymal extinction in human cirrhosis. Hepatology 2015, 61:1696-1707

62. Richardson MM, Jonsson JR, Powell EE, Brunt EM, NeuschwanderTetri BA, Bhathal PS, Dixon JB, Weltman MD, Tilg H, Moschen AR, Purdie DM, Demetris AJ, Clouston AD: Progressive fibrosis in nonalcoholic steatohepatitis: association with altered regeneration and a ductular reaction. Gastroenterology 2007, 133:80-90

63. Kuramitsu K, Sverdlov DY, Liu SB, Csizmadia E, Burkly L, Schuppan D, Hanto DW, Otterbein LE, Popov Y: Failure of fibrotic liver regeneration in mice is linked to a severe fibrogenic response driven by hepatic progenitor cell activation. Am J Pathol 2013, 183: 182-194

64. Williams MJ, Clouston AD, Forbes SJ: Links between hepatic fibrosis, ductular reaction, and progenitor cell expansion. Gastroenterology 2014, 146:349-356

65. Dubuquoy L, Louvet A, Lassailly G, Truant S, Boleslawski E, Artru F, Maggiotto F, Gantier E, Buob D, Leteurtre E, Cannesson A, Dharancy S, Moreno C, Pruvot FR, Bataller R, Mathurin P: Progenitor cell expansion and impaired hepatocyte regeneration in explanted livers from alcoholic hepatitis. Gut 2015, 64:1949-1960

66. Sancho-Bru P, Altamirano J, Rodrigo-Torres D, Coll M, Millan C, Jose Lozano J, Miquel R, Arroyo V, Caballeria J, Gines P, Bataller R: Liver progenitor cell markers correlate with liver damage and predict short-term mortality in patients with alcoholic hepatitis. Hepatology 2012, 55:1931-1941

67. Cai X, Zhai J, Kaplan DE, Zhang Y, Zhou L, Chen X, Qian G, Zhao Q, Li Y, Gao L, Cong W, Zhu M, Yan Z, Shi L, Wu D, Wei L, Shen F, Wu M: Background progenitor activation is associated with recurrence after hepatectomy of combined hepatocellular-cholangiocarcinoma. Hepatology 2012, 56:1804-1816

68. Soltys KA, Soto-Gutierrez A, Nagaya M, Baskin KM, Deutsch M, Ito R, Shneider BL, Squires R, Vockley J, Guha C, RoyChowdhury J, Strom SC, Platt JL, Fox IJ: Barriers to the successful treatment of liver disease by hepatocyte transplantation. J Hepatol 2010, 53:769-774

69. Puppi J, Strom SC, Hughes RD, Bansal S, Castell JV, Dagher I, Ellis EC, Nowak G, Ericzon BG, Fox IJ, Gomez-Lechon MJ, Guha C, Gupta S, Mitry RR, Ohashi K, Ott M, Reid LM, Roy-Chowdhury J, Sokal E, Weber A, Dhawan A: Improving the techniques for human hepatocyte transplantation: report from a consensus meeting in London. Cell Transplant 2012, 21:1-10

70. Fox IJ, Chowdhury JR, Kaufman SS, Goertzen TC, Chowdhury NR, Warkentin PI, Dorko K, Sauter BV, Strom SC: Treatment of the Crigler-Najjar syndrome type I with hepatocyte transplantation. N Engl J Med 1998, 338:1422-1426

71. Jorns C, Nowak G, Nemeth A, Zemack H, Mork LM, Johansson H, Gramignoli R, Watanabe M, Karadagi A, Alheim M, Hauzenberger D, van Dijk R, Bosma PJ, Ebbesen F, Szakos A, Fischler B, Strom S, Ellis E, Ericzon BG: De novo donor-specific HLA antibody formation in two patients with Crigler-Najjar syndrome type I following human hepatocyte transplantation with partial hepatectomy preconditioning. Am J Transplant 2016, 16:1021-1030

72. Dagher I, Boudechiche L, Branger J, Coulomb-Lhermine A, Parouchev A, Sentilhes L, Lin T, Groyer-Picard MT, Vons C, Hadchouel M, Pariente D, Andreoletti M, Franco D, Weber A: Efficient hepatocyte engraftment in a nonhuman primate model after partial portal vein embolization. Transplantation 2006, 82: 1067-1073

73. Yamanouchi K, Zhou H, Roy-Chowdhury N, Macaluso F, Liu L, Yamamoto T, Yannam GR, Enke C, Solberg TD, Adelson AB, Platt JL, Fox IJ, Roy-Chowdhury J, Guha C: Hepatic irradiation 
augments engraftment of donor cells following hepatocyte transplantation. Hepatology 2009, 49:258-267

74. Darwish AA, Sokal E, Stephenne X, Najimi M, de Goyet Jde V, Reding R: Permanent access to the portal system for cellular transplantation using an implantable port device. Liver Transpl 2004, 10: $1213-1215$

75. Takahashi K, Yamanaka S: Induction of pluripotent stem cells from mouse embryonic and adult fibroblast cultures by defined factors. Cell 2006, 126:663-676

76. Hannoun Z, Steichen C, Dianat N, Weber A, DubartKupperschmitt A: The potential of induced pluripotent stem cell derived hepatocytes. J Hepatol 2016, 65:182-199

77. Espejel S, Roll GR, McLaughlin KJ, Lee AY, Zhang JY, Laird DJ, Okita K, Yamanaka S, Willenbring H: Induced pluripotent stem cellderived hepatocytes have the functional and proliferative capabilities needed for liver regeneration in mice. J Clin Invest 2010, 120: $3120-3126$

78. Huang P, He Z, Ji S, Sun H, Xiang D, Liu C, Hu Y, Wang X, Hui L: Induction of functional hepatocyte-like cells from mouse fibroblasts by defined factors. Nature 2011, 475:386-389

79. Huang P, Zhang L, Gao Y, He Z, Yao D, Wu Z, Cen J, Chen X, Liu C, Hu Y, Lai D, Hu Z, Chen L, Zhang Y, Cheng X, Ma X, Pan G, Wang X, Hui L: Direct reprogramming of human fibroblasts to functional and expandable hepatocytes. Cell Stem Cell 2014, 14: 370-384

80. Yu B, He ZY, You P, Han QW, Xiang D, Chen F, Wang MJ, Liu CC, Lin XW, Borjigin U, Zi XY, Li JX, Zhu HY, Li WL, Han CS, Wangensteen KJ, Shi Y, Hui LJ, Wang X, Hu YP: Reprogramming fibroblasts into bipotential hepatic stem cells by defined factors. Cell Stem Cell 2013, 13:328-340
81. Zhu S, Rezvani M, Harbell J, Mattis AN, Wolfe AR, Benet LZ, Willenbring H, Ding S: Mouse liver repopulation with hepatocytes generated from human fibroblasts. Nature 2014, 508:93-97

82. Chen Y, Li Y, Wang X, Zhang W, Sauer V, Chang CJ, Han B, Tchaikovskaya T, Avsar Y, Tafaleng E, Madhusudana Girija S, Tar K, Polgar Z, Strom S, Bouhassira EE, Guha C, Fox IJ, RoyChowdhury J, Roy-Chowdhury N: Amelioration of hyperbilirubinemia in Gunn Rats after transplantation of human induced pluripotent stem cell-derived hepatocytes. Stem Cell Rep 2015, 5: 22-30

83. Carpentier A, Tesfaye A, Chu V, Nimgaonkar I, Zhang F, Lee SB, Thorgeirsson SS, Feinstone SM, Liang TJ: Engrafted human stem cell-derived hepatocytes establish an infectious HCV murine model. J Clin Invest 2014, 124:4953-4964

84. Collin de l'Hortet A, Takeishi K, Guzman-Lepe J, Handa K, Matsubara K, Fukumitsu K, Dorko K, Presnell SC, Yagi H, SotoGutierrez A: Liver-regenerative transplantation: regrow and reset. Am J Transplant 2016, 16:1688-1696

85. Camp JG, Sekine K, Gerber T, Loeffler-Wirth H, Binder H, Gac M, Kanton S, Kageyama J, Damm G, Seehofer D, Belicova L, Bickle M, Barsacchi R, Okuda R, Yoshizawa E, Kimura M, Ayabe H, Taniguchi H, Takebe T, Treutlein B: Multilineage communication regulates human liver bud development from pluripotency. Nature 2017, 546:533-538

86. Stevens KR, Scull MA, Ramanan V, Fortin CL, Chaturvedi RR, Knouse KA, Xiao JW, Fung C, Mirabella T, Chen AX, McCue MG, Yang MT, Fleming HE, Chung K, de Jong YP, Chen CS, Rice CM, Bhatia SN: In situ expansion of engineered human liver tissue in a mouse model of chronic liver disease. Sci Transl Med 2017, 9: eaah5505 